This item was submitted to Loughborough's Research Repository by the author.

Items in Figshare are protected by copyright, with all rights reserved, unless otherwise indicated.

\title{
Intercooled aero-gas-turbine duct aerodynamics: core air delivery ducts
}

PLEASE CITE THE PUBLISHED VERSION

http://dx.doi.org/10.2514/1.B34450

\section{PUBLISHER}

(c) American Institute of Aeronautics and Astronautics

\section{VERSION}

AM (Accepted Manuscript)

\section{PUBLISHER STATEMENT}

This work is made available according to the conditions of the Creative Commons Attribution-NonCommercialNoDerivatives 4.0 International (CC BY-NC-ND 4.0) licence. Full details of this licence are available at: https://creativecommons.org/licenses/by-nc-nd/4.0/

\section{LICENCE}

CC BY-NC-ND 4.0

\section{REPOSITORY RECORD}

Walker, Alastair Duncan, Gavita S. Regunath, Jonathan F. Carrotte, and Paul A. Denman. 2015. "Intercooled Aero-gas-turbine Duct Aerodynamics: Core Air Delivery Ducts". figshare. https://hdl.handle.net/2134/19071. 


\title{
Intercooled Aero Gas Turbine Duct Aerodynamics: Core Air Delivery Ducts
}

\author{
A Duncan Walker ${ }^{1}$, Gavita S Regunath ${ }^{2}$, Jon F Carrotte ${ }^{3}$ and Paul A Denman ${ }^{4}$ \\ Dept. of Aero and Automotive Engineering, Loughborough University, U.K.
}

The development of radical new aero engine technologies will be key to delivering the step-changes in aircraft environmental performance required to meet future emissions legislation. Intercooling has the potential for higher overall pressure ratios, enabling reduced fuel consumption, and/or lower compressor delivery air temperatures and therefore reduced NOx. This paper considers the aerodynamics associated with the complex ducting system that would be required to transfer flow from the core engine path to the heat exchanger system. The cycle benefits associated with intercooling could be offset by the pressure losses within this ducting system and/or any detrimental effect the system has on the surrounding components. A suitable branched S-shaped duct system has been numerically developed which diffuses and delivers the flow from the engine core to discrete intercooler modules. A novel swirling duct concept was used to locally open larger spacing between certain duct branches in order to provide engine core access whilst hiding the resultant pressure field from the upstream turbomachinery. The candidate duct system was experimentally evaluated on a bespoke low speed, fully annular isothermal test facility. Aerodynamic measurements demonstrated the ability of the design to meet the stringent aerodynamic and geometric constraints.

\footnotetext{
${ }^{1}$ Lecturer in Applied Aerodynamics, e-mail: a.d.walker@lboro.ac.uk

${ }^{2}$ Research Associate, e-mail: g.s.regunath@lboro.ac.uk

${ }^{3}$ Reader in Experimental Propulsion Aerodynamics, e-mail: j.f.carrotte@lboro.ac.uk

${ }^{4}$ Research Fellow, e-mail: p.a.denman@lboro.ac.uk
} 


\section{Nomenclature}

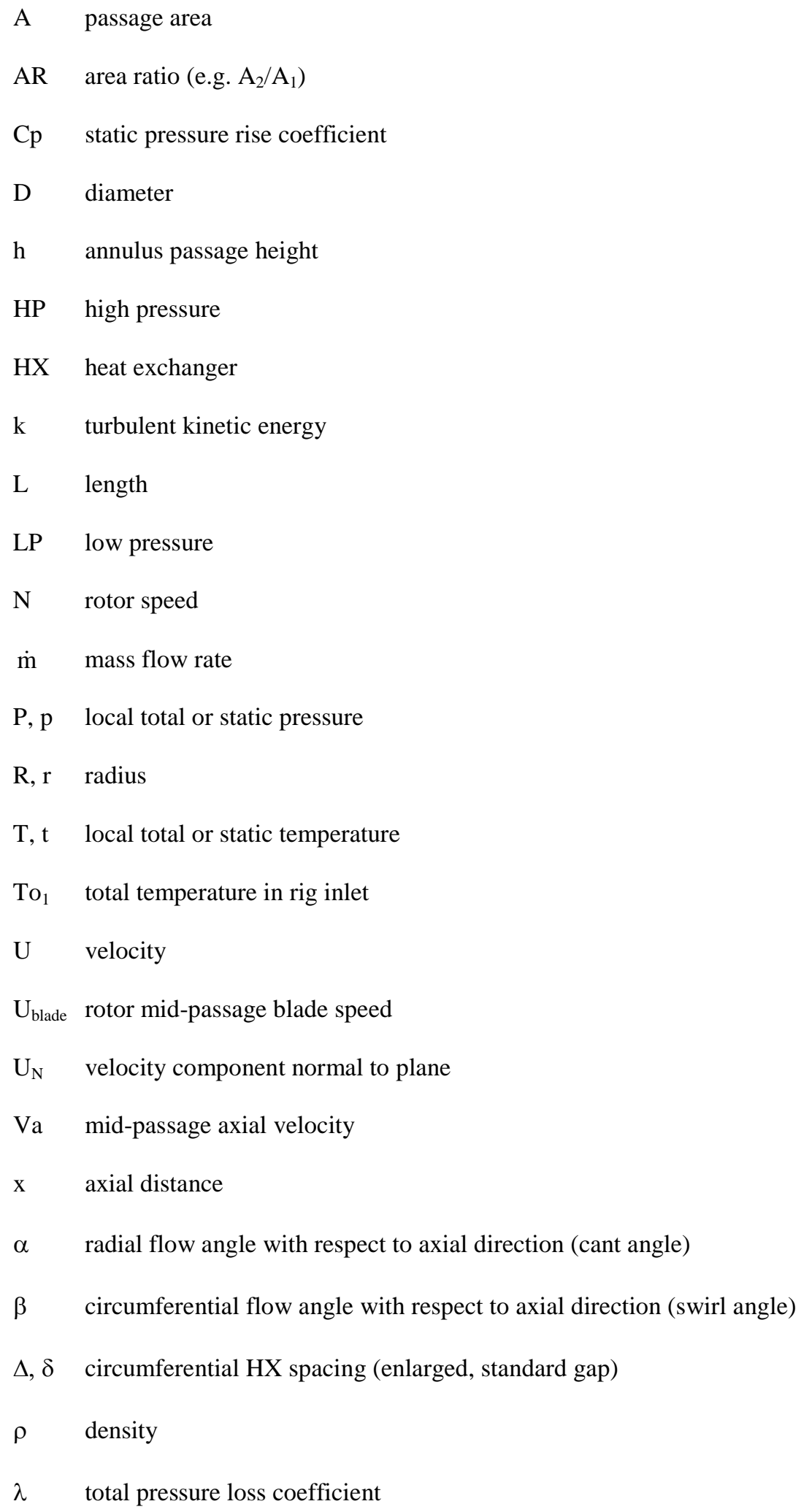




\section{Superscripts:}

- $\quad$ area weighted spatially averaged mean value

$\sim \quad$ mass weighted spatially averaged mean value

\section{Subscripts:}

1, 2 arbitrary inlet, outlet stations

X0 rig inlet traverse plane

X1 rotor inlet traverse plane

$\mathrm{Z} \quad$ rotor exit traverse plane

A OGV exit traverse plane

B diffuser exit traverse plane

C1-3 inner annulus traverse planes 


\section{Introduction}

Various technologies are being explored in order to meet the required improvements in future aircraft emissions as defined, for example, by the goals set in the ACARE Vision 2020 report [1]. One such technology is intercooling. This potentially offers significant $\mathrm{NO}_{\mathrm{x}}$ and/or fuel burn benefits with Wilfert et al. [2] suggesting practical reductions of order $16 \%\left(\mathrm{NO}_{\mathrm{x}}\right)$ and $4 \%$ (SFC). Furthermore, intercooling is potentially applicable across a broad product range from regional jets to large turbofans. It can also be applied to new and/or novel concepts such as geared turbofans, counter rotating fans and open rotor propfans. Although intercooling has been successfully used in land-based gas turbines the critical heat exchanger modules and ducting systems are currently too large to be incorporated within an aero gas turbine application. The potential benefits of intercooling are sensitive to the performance of these components and they must be given careful consideration in the design process.

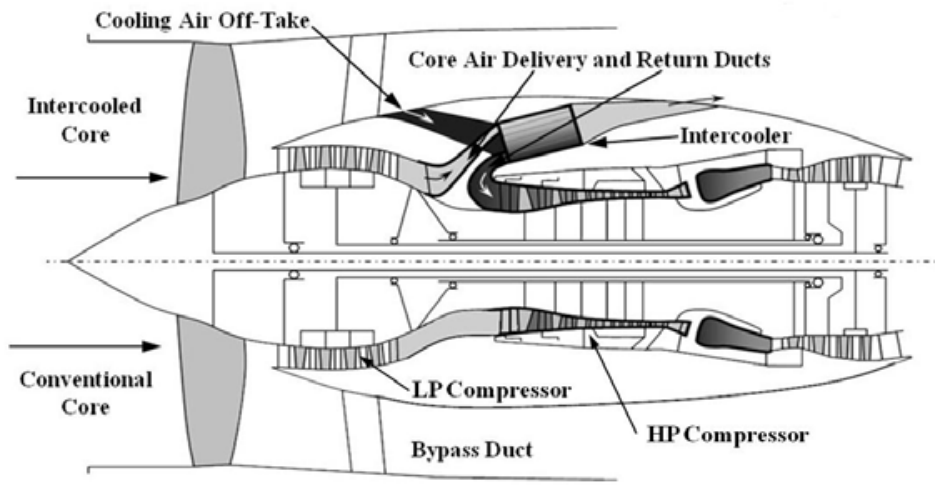

Figure 1 Intercooled Aero Engine Concept

In an intercooled aero engine the main core flow must pass through a heat exchanger system located upstream of the HP compressor spool (Figure 1). It is undesirable to increase the axial gap between compressor spools since this will add to engine length and weight. Given its physical size this means that the heat exchanger must be located outboard of the core path. It is also likely that the heat exchanger would consist of a number of discrete modules in order to (i) maximize surface area and effectiveness, (ii) minimize the impact of the installation on the engine diameter and, (iii) facilitate maintenance access and assembly requirements. Prior to entering each heat exchanger module the flow must also be diffused to maintain an acceptable total pressure loss. Hence aerodynamic ducting systems are required to transfer the flow from the exit of the upstream compressor spool to the individual heat exchanger modules (i.e. the core air delivery ducts) and then return the flow issuing from these modules to the 
downstream compressor spool (i.e. the core air return ducts). These complex ducting systems must be compact, lightweight and have low aerodynamic loss. If the aerodynamic penalties associated with the transition ducts are too high then the benefits of intercooling are negated and the concept is not viable. Furthermore, to achieve the high levels of cooling efficiency required the system must also provide a uniform flow distribution through the heat exchanger modules. However, as suggested by Cumpsty [3], the difficulty of achieving flow uniformity to the various heat exchangers without excessive pressure loss or duct-work that results in a large, bulky engine should not be underestimated.

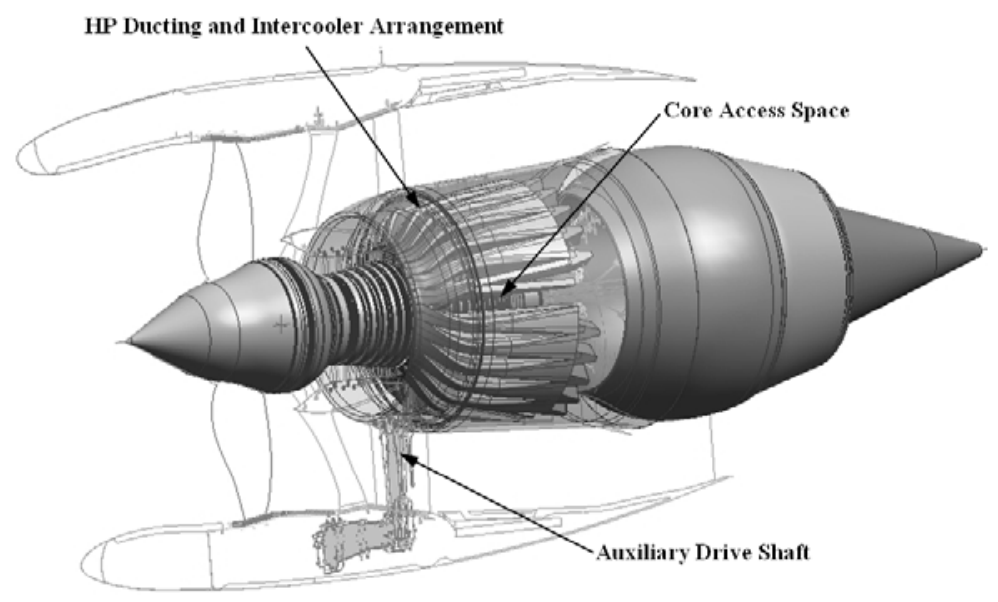

Figure 2 Intercooler Arrangement

This paper considers the design requirements and performance of the core air delivery duct. The diffusing nature of these ducts and the requirement to divide and supply equal amounts of flow to the individual heat exchanger modules makes design of these ducts particularly challenging. A companion paper will outline the design of the core air return ducts in which the flow is re-accelerated, returned to the axial direction and delivered to the downstream compressor spool. This companion paper will also review the aerodynamic performance of the complete intercooler system (i.e. the core air delivery and return ducts). Furthermore, a separate study has also been conducted by A'Barrow et al. $[4,5]$ to investigate the low-pressure duct system required to bleed air from the bypass duct and provide cooling air (refer to Figure 1). To ensure the use of realistic constraints the ducting system is targeted at the intercooled engine concept defined within the NEWAC EU Framework 6 Program [2] (Figures 1-2). This engine design study is for a 70,000lbf thrust, high by-pass ratio turbofan engine optimized for a long-range twin-engine aircraft. The work reported herein was aimed at the development of a design concept, numerical design method and 
ultimately proof of concept. Consequently the design is based on the cruise operating condition and off-design operation is not considered here. Within the current paper the core air duct requirements are discussed with respect to the basic geometry, local mechanical constraints and aerodynamic performance criteria. An initial design concept is described and the design space explored using RANS CFD. Consequently a numerical duct design methodology is presented and candidate geometries developed. After further CFD analysis of these candidate designs an experimental evaluation of the design concept is also presented. This utilized a purpose-built, low-speed test facility incorporating bespoke $1 \frac{1}{2}$ stage axial compressor which provided representative inlet condition to the duct system. Aerodynamic data were collected on a number of planes within the duct system, via the use of miniature five-hole probes, and these are presented and used to quantify the aerodynamic performance of the core air delivery duct system.

\section{Core Air Delivery Duct Requirements}

With reference to Figure 3 the design criteria for the core air delivery duct system can be divided into three main areas:

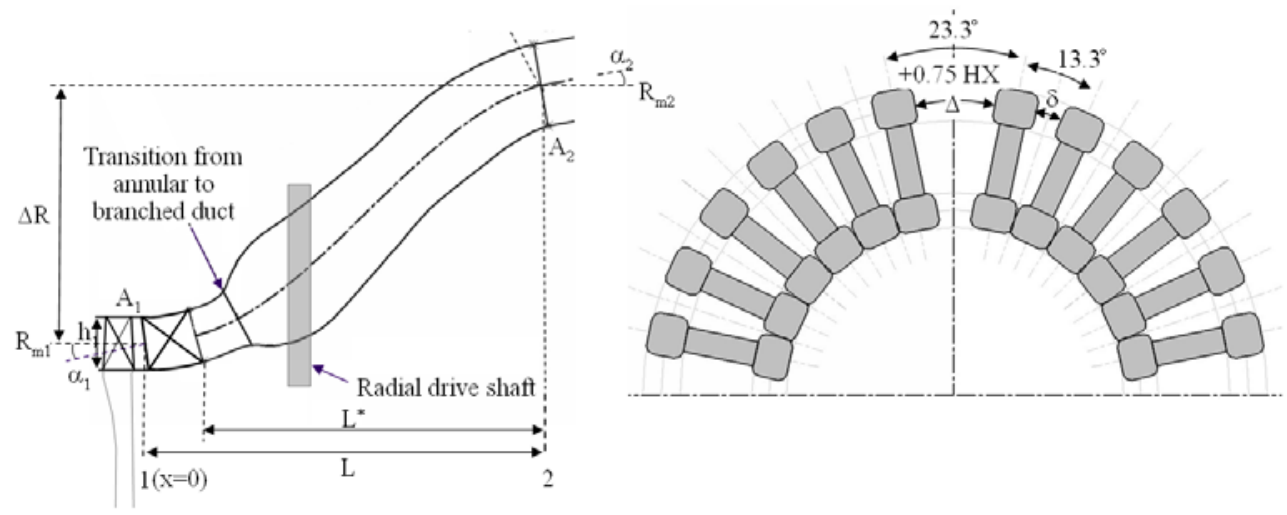

Figure 3 Basic Geometrical Parameters and Heat Exchanger Spacing

1. Basic Geometrical Requirements: These are mainly set by the position of the inlet and exit planes which correspond, respectively, to the exit of the upstream compressor spool and the intercooler (i.e. heat exchanger) inlet manifolds. From these, four basic aerodynamic non-dimensional parameters can be defined. The area ratio $\left(A_{2} / A_{1}\right)$ sets the bulk diffusion of the fluid and the non-dimensional radius change $(\Delta R / L)$ determines the level of curvature induced pressure gradients (also reflected by the mean radius ratio $\left(\mathrm{R}_{\mathrm{m} 2} / \mathrm{R}_{\mathrm{m} 1}\right)$ ). Hence, in 
conjunction with the area ratio and non-dimensional radius change, the non-dimensional length $\left(\mathrm{L} / \mathrm{h}_{1}\right)$ defines the severity of the streamwise pressure gradients. Additionally, the number of discrete intercooler modules sets the number of branches in the duct system and hence the nominal circumferential spacing $(\delta)$ between the inlet manifolds. These basic requirements suggest a diffusing S-duct type system within which the annular passage, at exit from the upstream compressor spool, is divided into a number of discrete passages (one supplying each manifold).

2. Local Mechanical Constraints: A gas turbine engine has several local mechanical requirements such as the need for a radial drive shaft (Figure 2) and core engine access for ancillary services. In a conventional engine these features cross the gas path via struts within the inter-compressor duct. However, in intercooler core air delivery ducts the wakes from such features would have an unacceptable impact on the efficiency of the downstream intercooler module. Hence, to maximize performance these features should located out of the main gas path and, if possible, between the branches of the S-duct. Unfortunately, uniformly distributed intercooler modules are unlikely to afford wide enough gaps for these features. Extra room must be created by incorporating non-uniform or asymmetric spacing of the intercooler modules, with larger gaps being generated at some circumferential positions. With reference to Figure 3 this gives rise to an increased offset $(\Delta)$ between certain modules and, as this gap increases, so the circumferential spacing between the remaining modules $(\delta)$ must reduce. However, these local variations can be detrimental to system performance. For example, they may decrease the uniformity of the flow being supplied to the various modules. They can also generate undesirable interactions with the upstream compressor spool. Nevertheless such features must be accommodated within the design concept.

\section{Aerodynamic Performance Criteria:}

(i) Overall Performance: The total pressure loss must be minimized and static pressure recovery maximized while turning and diffusing the flow within the given geometrical and mechanical constraints.

(ii) Upstream Component Interaction: The branching of the duct and the non-uniform spacing can produce upstream pressure perturbations leading to undesirable forcing of the upstream rotor. This is of particular significance when the rotor forcing is of relatively low frequency (e.g. 1 or 2 pressure perturbations per revolution). Hence the design concept must consider the upstream pressure field produced by the ducting system. 
(iii) Flow distribution: For simplicity and ease of manufacture it is desirable to have interchangeable (i.e. identical) heat exchanger modules. Thus, in order to ensure the same high cooling efficiency for each module the S-shaped duct system must divide the flow equally between them. The difficulty of achieving the required level of flow uniformity is highlighted by Cumpsty [3] as one of the major challenges to intercooling in aero engines. How well the system is 'balanced' can be assessed by the variation of stagnation pressure loss between the individual duct branches and the similarity of the exit plane flow profiles.

\section{System Concept}

To reiterate, the core air delivery ducts must divide the compressor efflux into discrete passages, diffuse and turn the flow radially outboard, generate a non-uniform spacing and deliver a uniform flow distribution. All this must be achieved with a minimum of stagnation pressure loss. However, the presence of flow splitters and variations in circumferential spacing between intercooler modules can both generate an undesirable pressure field that can (i) lead to a non-uniform flow distribution, and (ii) interact with the upstream compressor spool. In order to avoid these two issues a novel design concept is illustrated in Figure 4. In conventional engines an OGV row generally removes the entire swirl component from the compressor exit flow prior to the transition duct. However, in this concept some amount of swirl is allowed to pass down the core delivery duct. By removing this swirl at different axial locations within the various branches an enlarged spacing can be created. The additional offset $(\Delta-\delta)$ that can be achieved is a function of the inlet swirl angle $(\beta)$ and system length $(L)$. Furthermore, the local effect of the radial drive shaft is eliminated by locating the shaft outside of the main gas path. Figure 4 also indicates the local static pressure perturbations at the estimated OGV exit and rotor exit planes for a six branch sector. This could, for example, be the equivalent to one of several quadrants which form the engine annulus. It can be seen there is no evidence in the upstream pressure field of the radial drive shaft or the increased intercooler spacing $(\Delta-\delta)$. In more conventional engines this shaft would normally create a once per revolution pressure perturbation. In an intercooled engine there could be a requirement for several enlarged gaps around the engine and this would have the potential to produce

several perturbations per revolution. Instead, a relatively large number of equi-spaced pressure perturbations are generated (one perturbation per intercooler module). This is analogous to a more conventional OGV row. In the example shown the pressure perturbation is $10 \%$ of the dynamic head at OGV exit, and is virtually non-existent at rotor exit. 

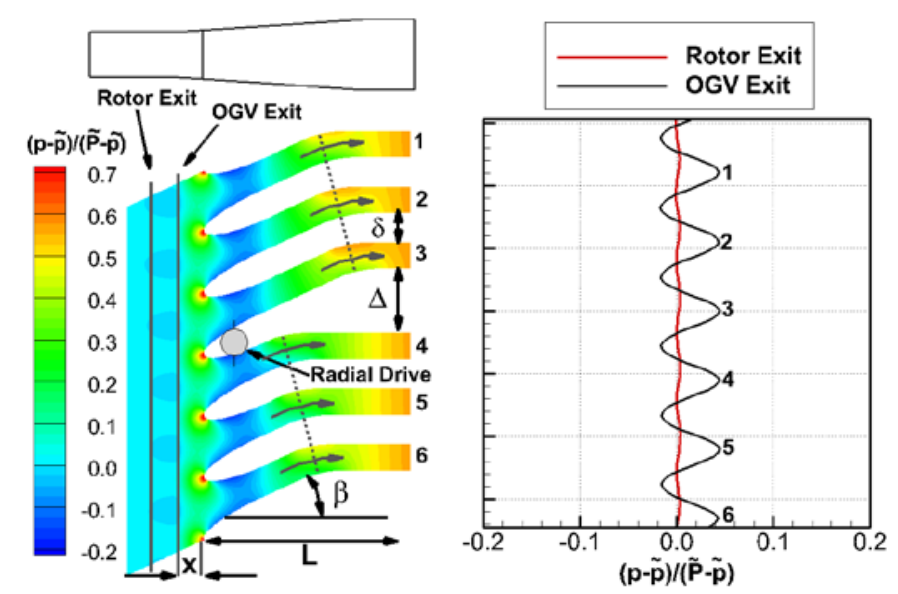

\section{(i) Developed View}

(ii) Normalized Static Pressure Variation

Figure 4 Swirling S-Duct Concept Static Pressure Contours

To explore the concept further RANS CFD predictions were made using a simplified planar model of a branched diffusing duct system (Figure 4). Although this simplified model contained no radial turning it had an area ratio of approximately 1.5 which is typical of the target value in the NEWAC engine. The predictions were undertaken using Fluent, the default linear pressure-strain Reynolds stress turbulence model and standard wall functions. These options were chosen in order to remain consistent with the methodology used in the more complex duct model presented in Section V. The predictions were run at isothermal conditions with a fixed, uniform inlet velocity condition based on the test facility design with an axial velocity of approximately $65 \mathrm{~ms}^{-1}$ (M 0.2) and a swirl angle ( $\beta$ ) of $25^{\circ}$. Fixed mass flow conditions were used at exit to each duct with periodic boundaries on the end walls. Although this fixes the mass flow distribution between ducts it was thought that this better reflects the engine where the high loss of the downstream heat exchanger modules will to some extent limit flow redistribution. The use of a zero gradient boundary condition allowed too much freedom. Examples of the predicted static pressure field for five different systems are presented in Figure 5. These include:

(i) An aerodynamically profiled (elliptical) leading edge for minimum loss,

(ii) A short circular leading edge increasing the length available for turning (hence increasing $\Delta$ ),

(iii) Leading edge as (i) but with thinner branches (smaller $\delta$ ) and an increased axial off-set (x) between the leading edge and "OGV" (i.e. reduce wetted area and loss),

(iv) As (iii) but larger spacing $(\Delta)$ achieved through profiling,

(v) As (iv) but further increase in spacing $(\Delta)$. 


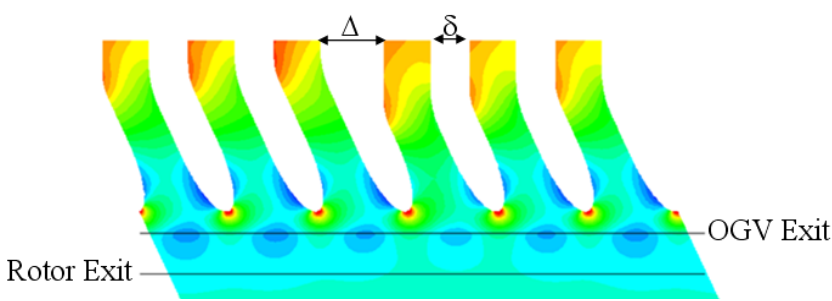

(i) $\lambda=0.113($ mean $),+0.005$ (max),- $0.003(\mathrm{~min})$

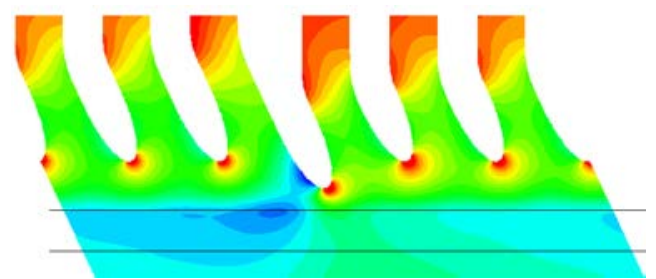

(iii) $\lambda=0.093$ (mean), +0.007 (max), -0.003 (min)

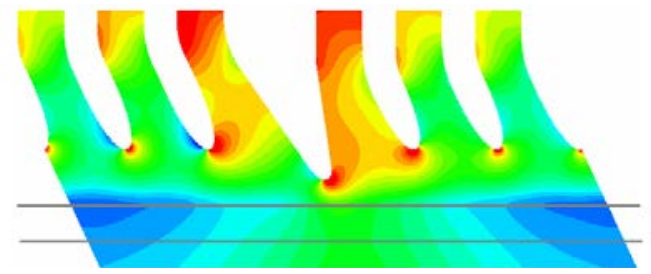

(v) $\lambda=0.107($ mean $),+0.018(\max ),-0.022(\min )$

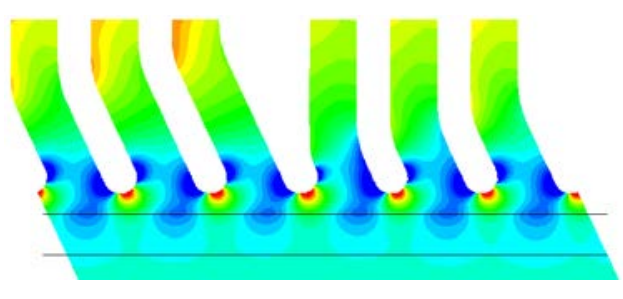

(ii) $\lambda=0.179($ mean $),+0.002(\max ),-0.002(\min )$

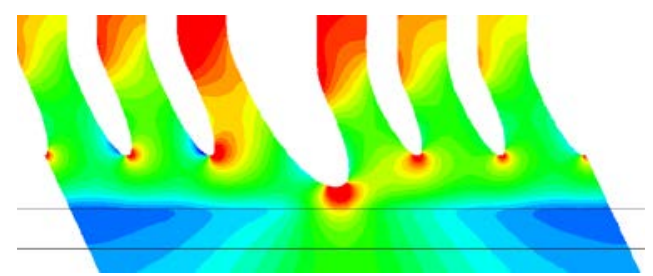

(iv) $\lambda=0.125($ mean),+0.007 (max), $-0.010(\min )$

$$
\lambda=\frac{\widetilde{\mathrm{P}}_{\text {inlet }}-\widetilde{\mathrm{P}}_{\text {duct exit }}}{\widetilde{\mathrm{P}}_{\text {inlet }}-\widetilde{\mathrm{p}}_{\text {inlet }}}
$$

$(\mathbf{p}-\tilde{\mathbf{p}}) /(\widetilde{\mathbf{P}}-\tilde{\mathbf{p}})$

$\begin{array}{cccccccccc}-0.20 & -0.10 & -0.00 & 0.10 & 0.20 & 0.30 & 0.40 & 0.50 & 0.60 & 0.70\end{array}$

Figure 5 Swirling S-Duct Concept Static Pressure Contours

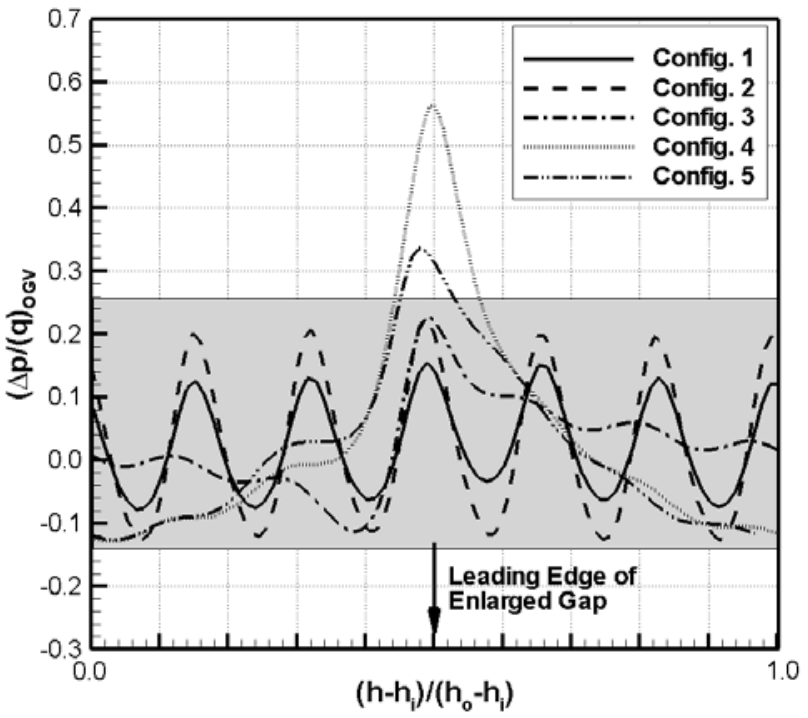

Figure 6 OGV Exit Static Pressure Distributions - Various Concepts 
The average loss coefficient for the six branches is also quoted along with the maximum and minimum values associated with individual branches. The loss coefficient is defined as the difference in mass-weighted stagnation pressure from the domain inlet to the exit of each branch normalized by the inlet dynamic pressure (see Figure 5). The average value is a relative measure of the system performance and the magnitude in the variation of the maximum and minimum values reflects how well the system is balanced. This is also indicated, to some extent, by the uniformity of the static pressure within the downstream ducts. Importantly, the simplified model also indicates upstream pressure field hence the potential for interaction with, and forcing of, the upstream turbo-machinery. For the OGV exit plane this is also shown in Figure 6 illustrating how the upstream pressure perturbation associated with the enlarged gap $(\Delta)$ is more evident for certain configurations. This also correlates with the flow in the six branches being less well-balanced. From these types of calculation a design space can be summarized (Figure 7) in terms of the trade-off between the various duct geometrical parameters and the aerodynamic performance (i.e. pressure loss, upstream pressure perturbation etc.).

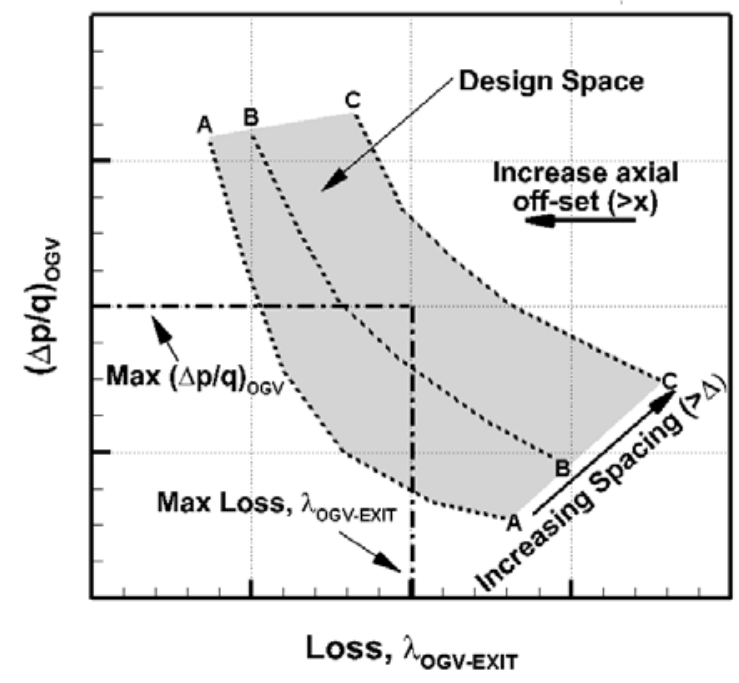

Figure 7 Design Space Performance

For a given intercooler spacing ( $\delta$ and $\Delta$ ) a well-balanced system with minimal interaction with the upstream turbo-machinery can be achieved but at the expense of higher stagnation pressure loss. These concepts are similar to (i) and (ii) above, and are located towards the bottom right hand corner of Figure 7. The system does exhibit some sensitivity to the flow field in the splitter leading edge region. The need to accommodate a radial drive shaft can significantly impact on the geometry in this region. However, the remaining branch inlets can be moved rearward, as in (iii), to produce an axial offset (x). This increased length prior to the splitter leading edges means that some extra 
diffusion can take place prior to the transition into discrete branches. Since the loss associated with this process is fundamentally a function of the dynamic head (i.e. velocity squared) this has a potential to reduce loss. However, this is at the expense of an increase in the local upstream pressure field perturbation (near the enlarged gap) and a less well balanced system. This is equivalent to moving along line A-A in Figure 7. Similarly, increasing the enlarged spacing $(\Delta)$, as in (iv) and (v), can potentially lead to higher losses and increased distortion of the pressure field and is equivalent to moving along lines B and C (Figure 7).

\section{Design Methodology}

Having outlined the concept it is necessary to determine if it can be successfully applied to an intercooled aero engine and to evaluate the performance of such a system. Hence the concept has been applied to the NEWAC intercooled engine [2]. In terms of the previously described design space it was decided to opt for a well-balanced system in which any interaction with the upstream compressor spool is minimized (i.e. no upstream pressure perturbations). Although this potentially produces a relatively high loss system it enables a datum system performance to be established (which can be linked to the requirements of the engine cycle without having to consider the effects, on engine performance, of unwanted interactions with the upstream turbo-machinery).

The NEWAC intercooled engine utilizes 24 discrete heat exchanger modules with the basic geometrical requirements of the ducting system being defined in Table 1 (see also Figure 3). Providing the necessary inlet swirl implies the need to integrate the OGV design with that of the S-duct system (i.e. the amount of turning undertaken by the OGV row is reduced to enable swirl to pass into the S-duct system). However, the level of integration can be further extended so that, for example, the OGV blade can be leant to provide a radial force component to help turn the flow radially outboard similar to that described by Britchford et al. [6]. Hence in the system being considered the OGV row is integrated into the first bend of the S-duct and provides, at inlet, $15^{\circ}$ of cant and $25^{\circ}$ of swirl. Where, the cant angle $(\alpha)$ is defined as the angle between the radial and axial flow components and similarly the swirl angle $(\beta)$ is defined as angle between the circumferential and axial flow components. The total system length (L) is defined as being from OGV inlet to duct exit, whilst $\mathrm{L}^{*}$ is the length from OGV exit to duct exit. The local mechanical constraints required for the NEWAC intercooled engine can be accommodated by providing enlarged spaces at four locations. The ducting system is therefore separated into four geometrically repeatable quadrants each

containing six branches (Figure 8). The pitch of the heat exchangers $(\delta)$ and the enlarged gaps $(\Delta)$ correspond to 
angles of $13.3^{\circ}$ and $23.3^{\circ}$ respectively. Furthermore the radial drive shaft is located at $30 \%$ of the system length (x/L $=0.3$ ) and has a diameter equivalent to $80 \%$ of the duct inlet height $\left(h_{1}\right)$. Hence the transition from an annular passage to discrete branches must occur upstream of this location. As already mentioned it is essential to diffuse the flow prior to the heat exchangers in order to minimize loses. In the NEWAC engine the requirement is to reduce the compressor exit Mach number by a factor of approximately 1.5 at heat exchanger inlet with a total pressure loss target of approximately $17 \%$ of the OGV exit dynamic pressure. Maximizing diffusion early in the duct system may be beneficial in that it (i) takes advantage of the increased mixing and turbulence associated with the OGV wakes, and (ii) reduces the diffusion in the second bend of the S-duct where separation is most likely. However, due to the complex nature of the flow it was decided that initially a nominally linear area increase would be employed.

\begin{tabular}{|c|c|}
\hline $\mathrm{L} / \mathrm{h}_{1}$ & 7.5 \\
\hline$\Delta \mathrm{R}_{\mathrm{m}} / \mathrm{L}$ & 0.7 \\
\hline $\mathrm{L}^{*} / \mathrm{h}_{1}$ & 6.8 \\
\hline$\Delta \mathrm{R}_{\mathrm{m}} / \mathrm{L}^{*}$ & 0.72 \\
\hline
\end{tabular}

\begin{tabular}{|c|c|}
\hline $\mathrm{A}_{2} / \mathrm{A}_{1}$ & 1.4 \\
\hline $\mathrm{R}_{\mathrm{m} 2} / \mathrm{R}_{\mathrm{m} 1}$ & 1.7 \\
\hline$\alpha_{1}$ & $+15^{\circ}$ \\
\hline$\alpha_{2}$ & $+10^{\circ}$ \\
\hline
\end{tabular}

Table 1 S-Duct Constraints (see Figure 3)

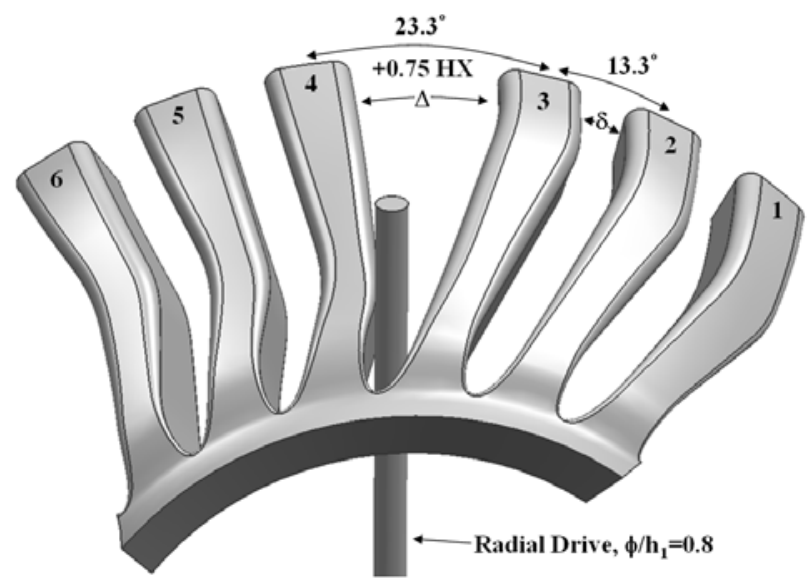

Figure 8 S-Duct Design (repeatable quadrant)

Whilst the ducting system requirements can be outlined, limited information is available to assist in the detailed design of such systems. For example, simple design charts for annular and conical diffusers are of limited use due to the curved and segmented nature of the ducting system. Hence published data can only provide some broad initial 
guidelines with numerical computational methods then being used to enable the detailed design and development of the ducting system. Finally, as in the current work, proof on concept must be demonstrated by suitable experimental validation.

\section{Numerical Concept Evaluation}

The numerical design method is outlined in detail by Walker et al. [4, 7] and was coded into MATLAB such that geometrical parameters could be easily changed, and the computational model rapidly regenerated, thus facilitating an iterative design process. In summary, a mean line was initially fitted to the baseline constraints using a complex Bezier curve. Suitable analytical functions were then used to control the variation in area ratio, aerodynamic blockage etc. enabling the duct model to be defined and extracted as a CAD wireframe. This was imported into UniGraphics to create a solid model, and then into Gambit to generate a computational model/mesh. Each duct branch was meshed with a predominately quadrilateral structured mesh which, following a grid dependency study, contained approximately one million nodes. Furthermore, non-uniform grid spacing was used to ensure wall $\mathrm{y}^{+}$ values were applicable to a wall function approach ( 30-60). RANS CFD predictions were undertaken using Fluent in conjunction with the default linear pressure-strain Reynolds stress turbulence model and standard wall functions. Eddy-viscosity turbulence models were considered but Britchford et al. [8] demonstrated that, for a compressor transition S-duct, a Reynolds stress model was much more able to capture the combined effects of strong pressure gradients and streamline curvature. They compared predicted data with LDA measurements of mean velocities and turbulent shear stresses. Although predictions with a Reynolds stress model still showed some discrepancies in the outer regions of the boundary layer (where the duct curvature affects turbulence production) they were more accurate than a k- $\varepsilon$ model. The use of low Reynolds number model (SST k- $\omega$ ) or Fluent's enhanced wall function to fully resolve the boundary layer was also considered as it is potentially more accurate. However, the increase in cell count necessary to achieve wall $\mathrm{y}+$ of 1-2 was excessive and prohibitive in terms of using these predictions in iterative design process. Similarly, given the available computational resources a numerical assessment of the entire quadrant (Figure 8) was not practical. Thus, the quadrant was broken into individual ducts and predictions undertaken for branches 1 (mid quadrant), 3 and 4 (either side of the enlarged gap) as shown in Figure 9. 


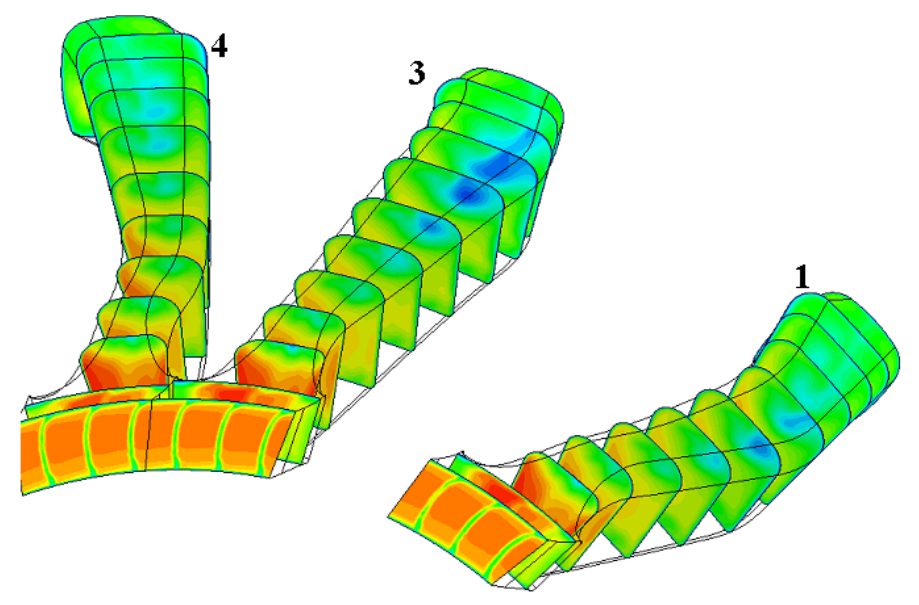

Figure 9 Predicted Stream-wise velocity contours

In order to provide representative duct inlet conditions (containing OGV wakes and secondary flows) to the experimental facility a bespoke $1 \frac{1}{2}$ stage axial compressor was numerically designed by Rolls-Royce plc (see Section VI). OGV exit data were extracted from this design prediction and used to define the inlet boundary conditions (including OGV wakes) for the duct development CFD. This provided a map of the three velocity components from which appropriate turbulence ( $\mathrm{k}$ and $\varepsilon$ ) data were approximated using established in-house techniques.

For each duct the swirl is removed at a different axial location and consequently in a different pressure field. For duct 1, swirl removal occurs at the point of inflection in the S-duct ( $50 \%$ length), where the radial pressure gradient will be approximately zero. Hence the flow will only be subjected to a diffusive pressure gradient along with an additional tangential pressure gradient to remove the swirl. However, for duct 4 the swirl removal occurs just after the $1^{\text {st }}$ bend where a radial pressure gradient is encouraging outboard migration and, for duct 3 the swirl is removed in the $2^{\text {nd }}$ bend where the radial pressure gradient will encourage inboard migration. Some examples of predicted streamwise velocity contours are presented in Figure 9. The OGV wakes are clearly visible in the inlet boundary condition but mix out quite rapidly and are no longer evident downstream of the transition point. However, acceleration of the flow around the leading edge of the transition point generates a high velocity region close to each sidewall with a low velocity region being generated in the outer portion of all three ducts. This deepens under the influence of the adverse pressure gradient within the $2^{\text {nd }}$ bend and tends to dominate the flow field. Particle traces (Figure 10) show that this is caused by secondary flows generated as the boundary layer negotiates the leading edge of the splitter which divides the annular passage into discrete branches. Horse-shoe vortices are created and combine 
to form a passage vortex [9] which tends to dominate the passage flows, with some differences being apparent between the different ducts. However, in general the flow within each duct is attached with the predicted pressure loss coefficient varying by $\sim 4 \%$ between ducts (Table 2 ) which suggests a well-balanced ducting system.

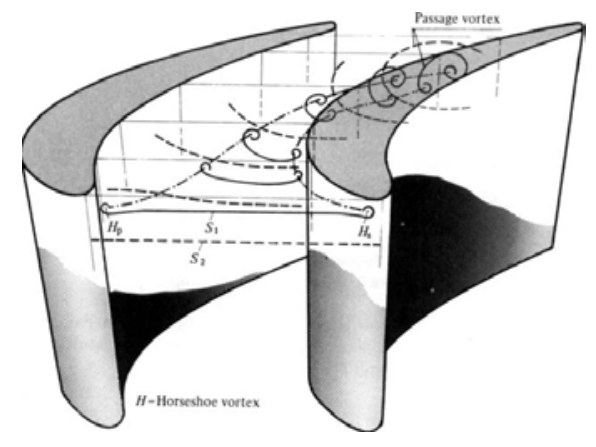

(a) Turbine Blade Row [9]

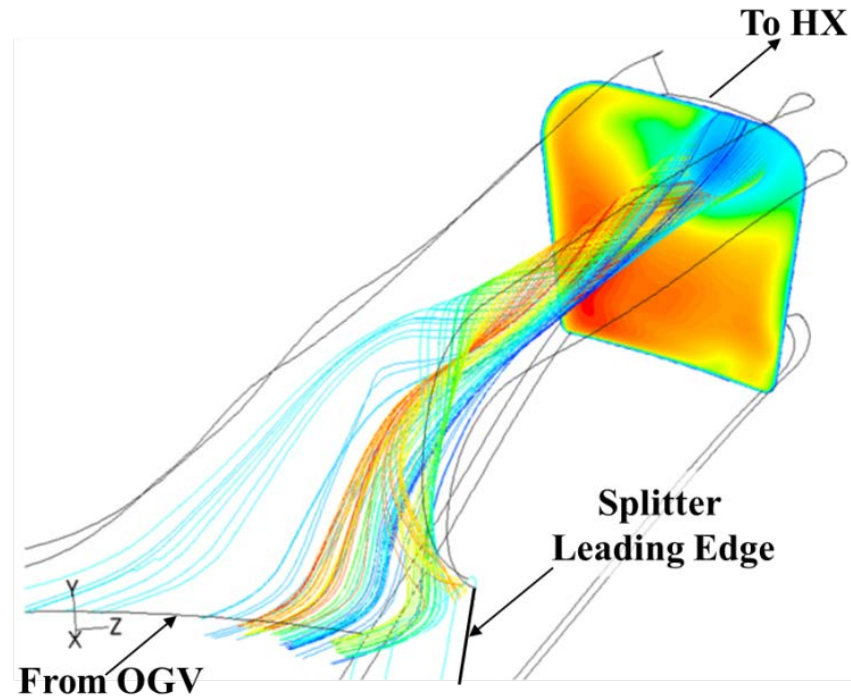

(b) S-Duct Branch [7]

Figure 10 Particle Tracks and Stream-wise Velocity Contours (Duct 3)

\begin{tabular}{|c|r|r|r|}
\hline Loss & Duct 1 & Duct 3 & Duct 4 \\
\hline$\lambda=\frac{\tilde{P}_{A}-\tilde{P}_{B}}{\tilde{P}_{A}-\tilde{p}_{A}}$ & 0.132 & 0.127 & 0.132 \\
\hline
\end{tabular}

Table 2 Predicted S-Duct Losses (A- OGV Exit, B - Duct Exit)

\section{Experimental Test Facility}

Experimental assessment of the ducting system was undertaken using a purpose built, low speed isothermal test facility (Figure 11) which is approximately $70 \%$ scale of the NEWAC intercooled aero-engine. Operating at nominally atmospheric conditions the fully annular rig is mounted vertically with ambient air being delivered by a centrifugal fan via an under-floor plenum chamber. It is widely acknowledged that the inlet conditions presented to diffusing ducts can have a crucial influence on the performance of those ducts, and the importance of compressor generated conditions has been reported in several detailed studies (Stevens et al. [10], Klein [11], Zierer [12], Carrotte et al. [13], and Barker et al. [14, 15]). Hence the facility utilized a 11/2 stage axial flow compressor upstream 
of the ducting system. This provides a good compromise in terms of capturing the blade wakes, secondary and rotor tip leakage flows etc. that will have an important influence on the downstream diffusing ducts whilst avoiding the costs associated with using a multi-stage compressor to provide the inlet conditions [16].

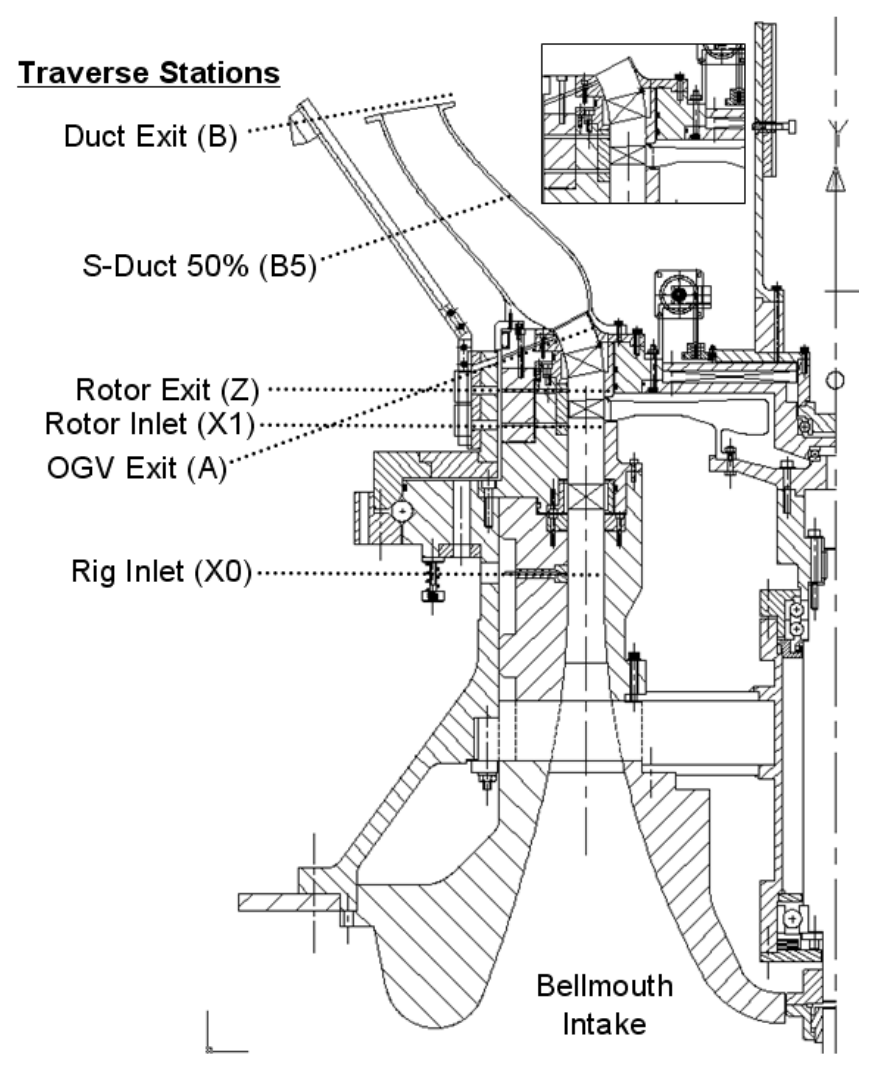

Figure 11 Test Section and Measurement Planes (Inset - Short Commissioning Diffuser)

Design of the axial flow compressor was undertaken in conjunction with Rolls-Royce plc. using established techniques and a propriety 3D CFD code $[17,18]$, with blade loadings and other aerodynamic loading parameters being broadly representative of current engine design practice. The compressor consists of a row of 72 pre-swirl vanes, a rotor with 86 blades and an OGV row with 72 vanes. The number of OGVs was set as an integer multiple of the number of intercooler modules to ensure each duct branch was presented with identical inlet conditions. The vane design also includes tangential lean in order to integrate the OGV into the first bend of the S-duct. Hence the OGV row has an exit cant angle $(\alpha)$ of $15^{\circ}$ reducing the radial turning requirements of the S-duct and shortening the system length. Further, to incorporate the swirling duct concept outlined earlier the vane row provides $25^{\circ}$ of swirl ( $\beta$ ) at the inlet to the core duct system. The actual operating speed was such as to typically maintain a Reynolds number, based on the OGV chord, of approximately $2 \times 10^{5}$ (i.e. above any transitional effects as described by 
Cumpsty [19]). This gave a total velocity at OGV exit velocity of around $75 \mathrm{~ms}^{-1}$ (or a Mach number close to 0.22 ) and a total rig mass flow of about $6.7 \mathrm{kgs}^{-1}$.

The test rig was designed to be modular such that experiments to determine the aerodynamic performance of the complete HP duct system could be performed. In the work presented here only the diffusing S-duct is considered. However, in a companion paper the complete system will be assessed. This will include (i) a heat exchanger model designed to replicate the core air flow path and loss, and (ii) the core air return duct system. Aerodynamic performance was mainly assessed using suitably calibrated miniature five-hole probes $(\phi=1.76 \mathrm{~mm})$ as described by Wray and Carrotte [16] and employed in a non-nulled mode to determine the local flow vector and total and static pressures. As indicated in Figure 11, area traverses could be conducted at rig inlet (X0), rotor inlet (I1), rotor exit (Z), OGV exit (B), 50\% S-duct (B5) and S-duct exit (B). Measurements were made in duct branches 1, 3 and 4.

\section{Data Reduction and Experimental Errors}

The compressor non-dimensional speed $\left(\mathrm{N} \pi \mathrm{D} / \sqrt{ }\left(\gamma \mathrm{RTo} \mathrm{o}_{1}\right)\right)$ and flow coefficient $\left(\mathrm{Va} / \mathrm{U}_{\text {blade }}\right)$ could be maintained to within $\pm 0.08 \%$ and $\pm 0.18 \%$ respectively of their prescribed values. Probes were traversed in the radial direction using a stepper motor powered linear guide with positional accuracy of better than $\pm 0.1 \mathrm{~mm}$. Circumferential probe movement (over a given repeatable sector) was achieved by rotating the inner and outer casings about the rig center line using a high-power stepper or DC servomotor and it is estimated that a probe can be positioned to within $\pm 0.05^{\circ}$ of the desired location. Overall aerodynamic performance was quantified in terms of total pressure loss and static pressure recovery coefficients derived from the five-hole probe area traverse data (corrected to ICAO standard day conditions). The mass flow balance between various area traverse planes was within $\pm 1 \%$ of the total mass flow entering the test facility measured via a five-hole probe traverse at plane I1. Spatially averaged values of total and static pressure at each plane were derived using the mass-weighted technique described by Klein [20] with the massweighted total pressure loss $(\lambda)$ and static pressure rise (Cp) coefficients then defined as:

$$
\lambda_{A-B}=\frac{\tilde{P}_{A}-\tilde{P}_{B}}{\tilde{P}_{A}-\tilde{p}_{A}} \text { and } \quad C_{p}=\frac{\tilde{p}_{B}-\tilde{p}_{A}}{\tilde{P}_{A}-\tilde{p}_{A}}
$$

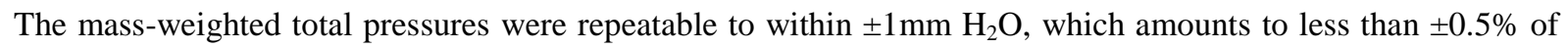
the dynamic pressure at OGV exit. Thus, the repeatability of the derived total pressure loss and static pressure rise coefficients was better than \pm 0.005 of the values presented. 


\section{Experimental Results and Discussion}

\section{Compressor/Ducting System Interaction}

Rotor Exit (Z): During the numerical design of the compressor a short annular diffuser, similar to the initial annular portion of the S-duct, was included in the solution domain in order to provide the correct pressure gradient at OGV exit. This was also replicated experimentally to commission the test rig and validate the compressor design. Importantly, this test also served as a datum enabling any effect of the ducting system on the compressor to be assessed. The basic aim of the design concept was to avoid any changes in the static pressure field at rotor exit generated by the presence of the ducting system. Achievement of this was confirmed by the experimental measurements at rotor exit (Z). Figure 12 plots rotor exit radial profiles generated from circumferentially averaging area traverse data measured over a two OGV $\left(10^{\circ}\right)$ sector. The plot confirms that, within experimental error, no difference was observed with the annular diffuser or S-ducts present. Note that in the latter case tests were performed over $10^{\circ}$ sectors both in line with, and midway between, the splitters which divide the downstream annular geometry into discrete ducts.

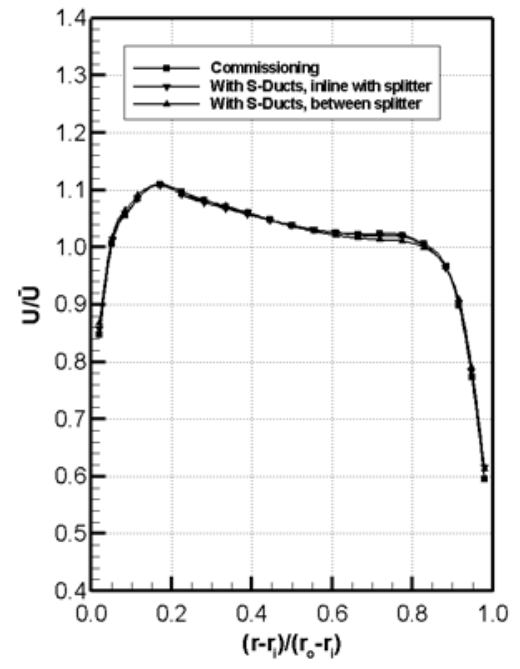

(a) Axial Velocity

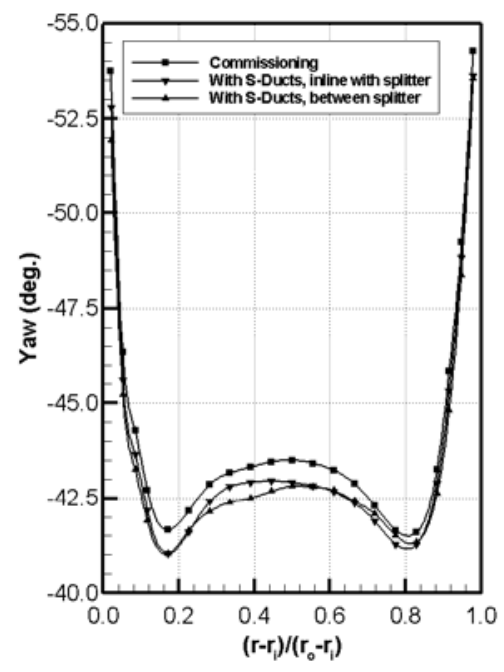

(b) Yaw Angle

Figure 12 Rotor Exit (Z) Circumferentially Averaged Profiles

OGV Exit (A): The OGV exit measurement plane (A) is located approximately one chord length downstream of the OGV row and two thirds of the distance between the OGV trailing edge and the point where the annular passage is divided into discrete branches. Consequently, the measurements here present a pessimistic view of the impact of the pressure field generated by each splitter on the upstream OGV row. The measured flow field is indicated in 
Figure 13 by contours of velocity (normal to the measurement plane) and static pressure. For the commissioning phase an area traverse relating to only two $\mathrm{OGV}\left(10^{\circ}\right)$ sector is presented, with this flow field being repeated around the remaining $350^{\circ}$ of the annulus. With the intercooler ducting system present measurements were undertaken over a $15^{\circ}$ (3 OGV) sector which corresponds to the sector occupied by a single duct. Results are presented for duct 1 (but similar results were obtained for ducts 3 and 4), with the measurements now showing evidence of the downstream ducting system. Deceleration of the flow occurs in line with the dividing splitters (i.e. at the sector extremities); whilst in the center of each sector the velocity field shows the flow starting to accelerate into the discrete duct branches. This also affects the mixing out of the OGV wakes around each sector. Evidence of these effects is also indicated by the static pressure field, which includes a radial pressure gradient associated with the outboard turning of the flow.

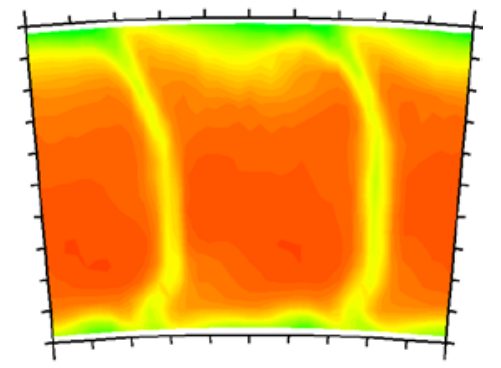

(a) Commissioning $\left(10^{\circ}\right.$ Sector $)$

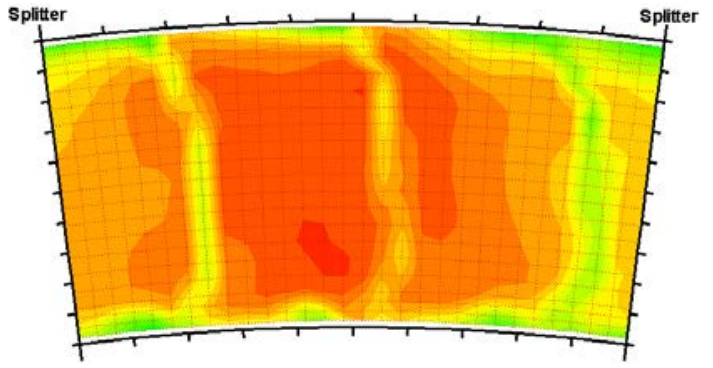

(b) Duct 1 (15 ${ }^{\circ}$ Sector $)$

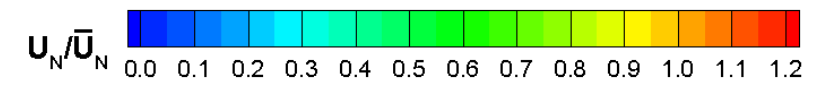

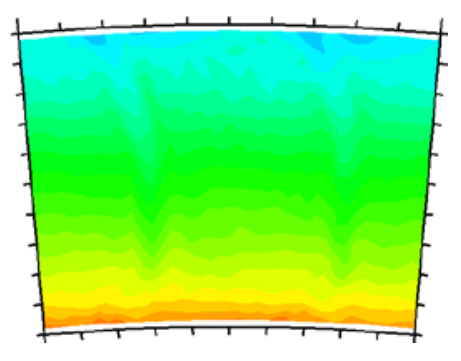

(a) Commissioning (10 ${ }^{\circ}$ Sector $)$

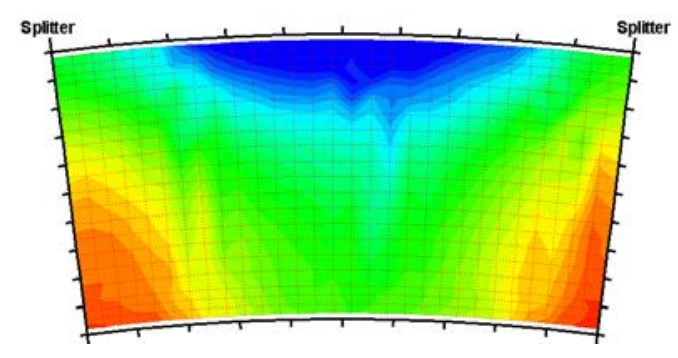

(b) Duct $1\left(15^{\circ}\right.$ Sector $)$

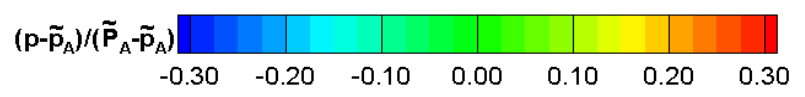

Figure 13 OGV Exit (A) Velocity and Static Pressure Contours 
As expected there are now 24 perturbations in the static pressure field measured at OGV exit associated with the 24 downstream splitters. However, despite the differing downstream geometry (including the enlarged gap between two of the branches), the upstream pressure perturbations associated with each branch of the system are identical (refer to Figure 14). Hence the results suggest the design intent has been met, i.e.

(i) At rotor exit no perturbations resulting from the downstream geometry are observed,

(ii) The peaks observed downstream of the OGV row associated with each splitter are identical (i.e. the larger circumferential offset between branches 3 and 4 is not evident). Hence 24 small perturbations are observed rather than four large ones, and

(iii) Similarity of the flow field entering each branch of the ducting system suggests a well-balanced system.

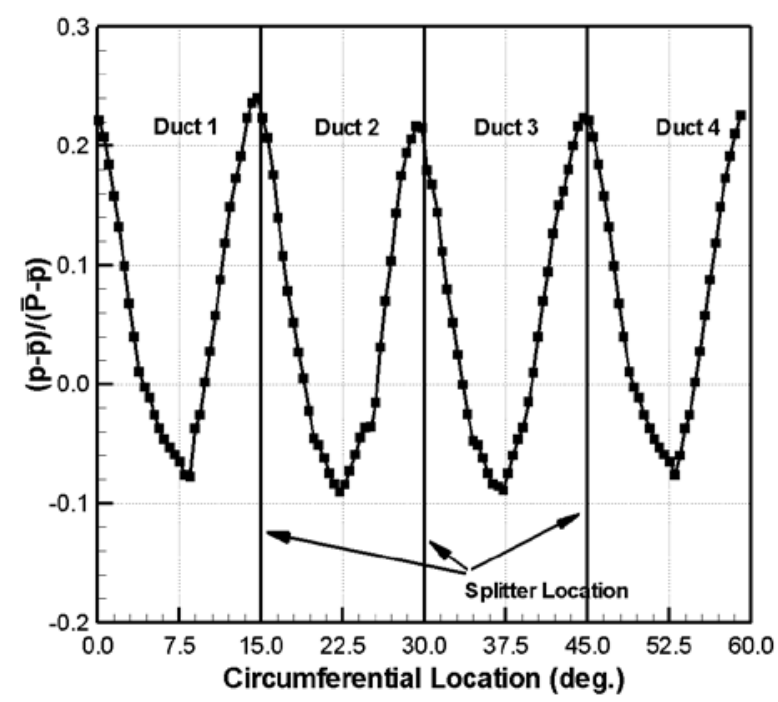

Figure 14 OGV Exit (A) Circumferentially Variation in Mid-height Static Pressure - Ducts 1 to 4

\section{Duct Flow Field Development}

Figure 15 plots the axial variation of the wall static pressure which reflects the diffusion and curvature undertaken by the flow within the ducting system. As the flow leaves the OGV in a traditional annular S-shape duct the inner wall static pressure is generally greater than the outer wall reflecting the outboard flow curvature within the first bend. However, this is not the case here. In the branched duct, to maintain a linear area increase, the blockage generated by the splitter results in local wall curvature which in turn modifies the local wall static pressure. Similarly, as the flow negotiates the transition from an annular to discrete passages it accelerates and the pressure on both walls decreases (note that the tappings are located circumferentially mid-passage). Once in the discrete passage the inner wall pressure remains higher than the outer wall until approximately mid duct length where the curvature 
falls to zero and then reverses in the second bend of the S-duct. There is a general trend for both inner and outer wall static pressure to increase which reflects the diffusing nature of the duct. Finally, as the flow negotiates the second bend and returns to the heat exchanger cant angle $(\alpha)$ of $10^{\circ}$, the inner wall pressure falls below that of the outer wall. Figure 15 also contains data from the CFD design showing good agreement with the measurements. In reality intercooler modules would be positioned downstream of the S-ducts with the potential to alter the flow field within the ducts. By allowing the S-duct efflux to exhaust to atmosphere, rather than pass through the heat exchanger modules, a better indication can be obtained of how well the core delivery duct system is balanced (i.e. the relatively high loss across the heat exchanger would act to balance the system). However, tests have been conducted which include simplified heat exchanger modules and the core air return duct system. In these tests, which will be reported in detail in a companion paper, the simplified heat exchanger modules were carefully designed to replicate the flow path of the core flow and the loss through the heat exchanger as anticipated in the NEWAC design. The associated wall static pressure data are included in Figure 15 and show that the variation is not significantly altered.

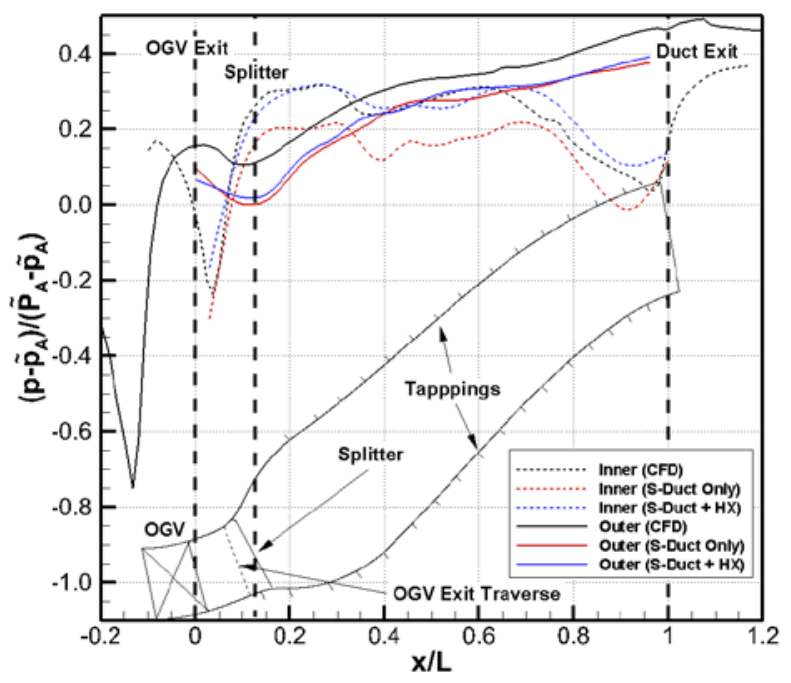

Figure 15 Wall Static Pressure - Duct 1

50\% Duct Length (B5): Velocity contours normal to the measurement plane are presented in Figure 16 along with the associated secondary flow vectors for duct branches 1, 3 and 4. All branches have an inboard bias inherited from the hub biased rotor exit pressure profile. With reference to Figures 4 and 5 branches 1 and 3 have yet to undergo circumferential turning and, with identical upstream geometry, exhibit an almost identical flow field with a large degree of swirl. However, for duct branch 4 the velocity profile is more uniform and with the swirl removed two counter rotating vortices are revealed. Post-processing of the data to remove the bulk swirl shows that these 
vortical structures are also present in duct branches 1 and 3 - see Figure 16(e) and (f). These are classic secondary flow vortices [9] generated as the end-wall boundary layer turns around the leading edge of the splitter (Figure 10). Horse-shoe vortices are created and then combine to form a passage. Although these vortices are a source of low velocity regions and loss, they also generate turbulence stirring up the flow and transferring higher momentum fluid into the boundary layers. This potentially delays separation. It is worth noting that the magnitude of the secondary flows will be determined by factors such as the boundary layer thickness, splitter leading edge thickness, flow turning and the velocity in this region. In the current design the splitter leading edge thickness was primarily determined by the size of the radial drive shaft. The flow turning, boundary layer thickness and velocity were mainly determined by the overall system requirements. For reference purposes Figure 16 also presents contours from the CFD design of duct branch 1 showing a reasonable level of agreement with the experimental data. However, despite predicting the magnitude of the secondary flows the CFD does not faithfully predict the location.

Duct Exit (B): Example velocity contours for duct 1 (Figure 17) show that, at duct exit, the flow remains relatively non-uniform retaining the upstream inboard bias in addition to a side wall bias generated by the circumferential turning. Similarly, velocity vectors indicate that the secondary flow vortices are still present. For each branch the exit flow exhibits broadly similar characteristics. In addition, the mass flow and total pressure loss derived from the measurements also show a good balance between the branches. For example the computed mass flow for each branch matched to within $1 \%$ and the total pressure loss coefficients to within $5 \%$ (of the inlet dynamic pressure). This suggests that the design methodology has been successful in producing a well-balanced ducting system. Furthermore the measured loss is close to the targets set for the intercooled cycle. Comparison with the numerical predictions indicates the measured loss coefficient is slightly higher than that predicted (Table 3). This was expected as experience has shown that for this type of prediction RANS CFD under predicts the total pressure loss associated with the mixing out of the OGV wakes. Britchford [8] demonstrated that a Reynolds Stress turbulence model is relatively good at capturing the flow in annular S-shaped ducts. However, the aerodynamics of the current branched duct system is much more complex incorporating strongly swirling flow and vortical structures in addition to streamline curvature and pressure gradients effects. Furthermore, the flow will be fundamentally unsteady thus it not surprising that there are differences between the measured and predicted flows using RANS CFD. Nevertheless the main flow field features appear to be captured by the numerical predictions and the methodology suitable for use in an iterative design process. 


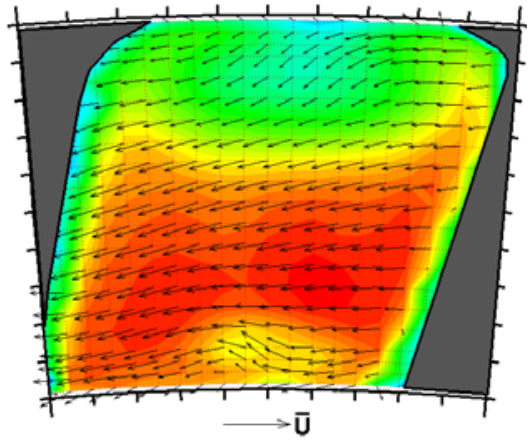

(a) Duct 1

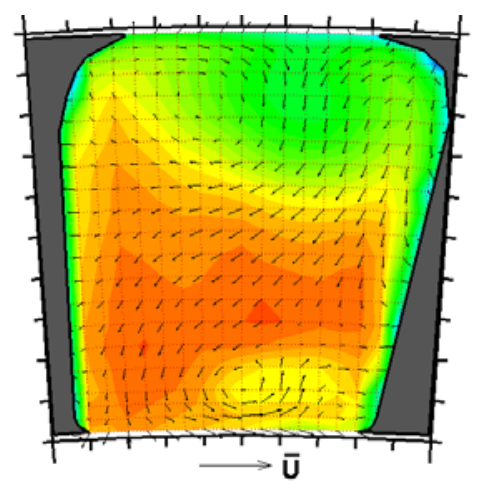

(c) Duct 4

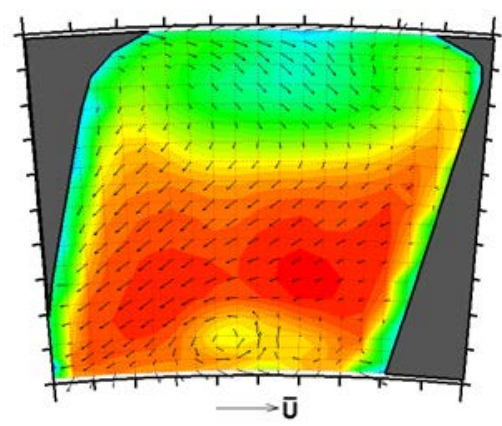

(e) Duct 1(average swirl removed)

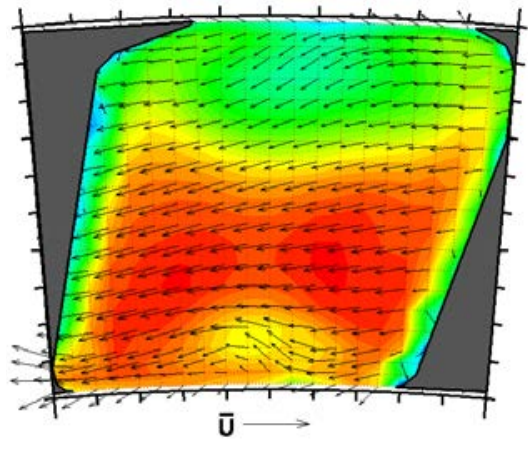

(b) Duct 3

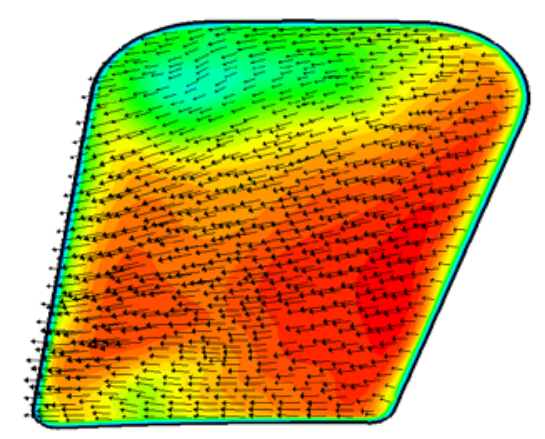

(d) Duct 1 - CFD

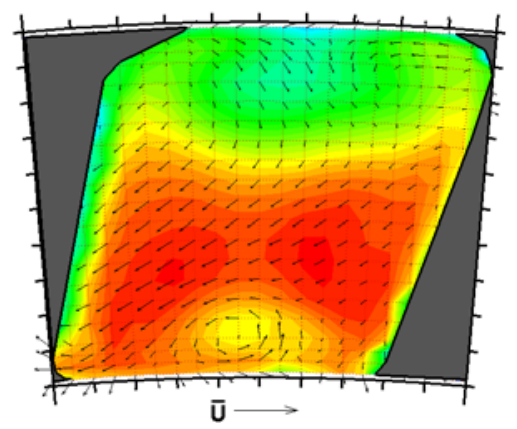

(f) Duct 3(average swirl removed)

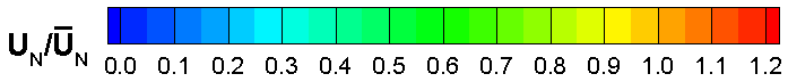

Figure $1650 \%$ Duct Length (B5) Normal Velocity Contours 


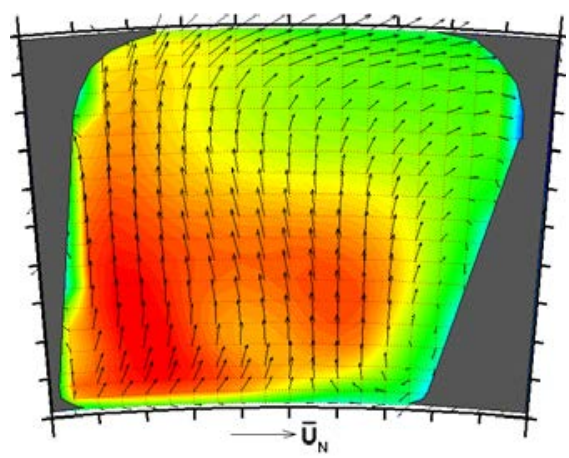

(a) Duct 1- Experimental

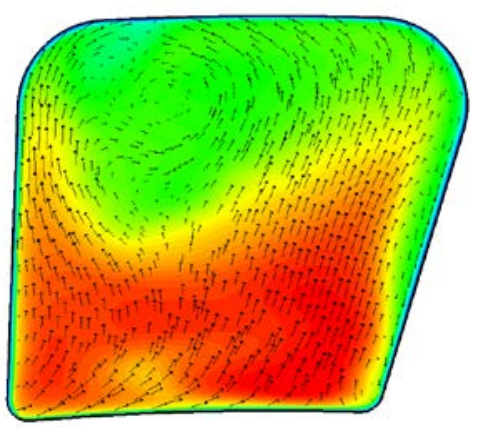

(b) Duct 1 - CFD

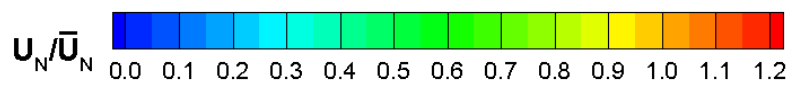

Figure 17 Duct Exit (B) Normal Velocity Contours

\section{System Development}

The combination of experimental measurements and numerical predictions enable the main sources of loss with the ducting system to be identified. These are: (1) fundamental loss from skin friction within the transfer duct; (2) mixing loss associated with OGV wakes; (3) loss due to diffusion; (4) impingement loss on the bluff leading edges; and (5) secondary flow losses. Plotting the production of turbulent kinetic energy can reveal areas where loss is generated. For example, Figure 18 shows plots for duct 3 for the side walls (a) and the internal flow planes (b) and (c). These plots reveal that losses (red) are generated within the OGV wakes (i.e. due to mixing), close to the walls (skin friction) and in the secondary flows. Each of these would appear to be of similar magnitude. However, Figure 18(a) shows that loss generated by the leading edge is at least an order of magnitude higher (note the change in contour legend). This is further illustrated by the development of the loss along the duct system derived from the numerical predictions (Figure 19). Note the rapid increase of loss within the leading edge region which therefore represents an important source of system loss and is consistent with the concepts and design space described in Figure 7.

Having developed an appropriate numerical design methodology along with the capability to experimentally validate different ducting systems a second geometry was designed and tested. The objective was to reduce system pressure loss and concentrated on the splitter leading edge region. For example, the same duct requirements can be met but with an increased amount of diffusion upstream of the transition point (the velocity and hence loss generated 
by the transition should therefore be reduced). In the original design the area changed linearly through the duct and resulted in a 5\% passage area increase between OGV exit and the leading edge of the splitters. However, numerical predictions suggested this could be increased to $15 \%$, whilst avoiding separation, resulting in a $7 \%$ loss reduction. Furthermore, if the splitter thickness could also be reduced then this would have a notable effect on loss. For example with the splitter thickness at $60 \%$ of its original value numerical predictions suggested a loss reduction of order $30 \%$. This latter change would be consistent with a radial drive shaft of smaller diameter, or a rearward movement of the shaft within the engine. This reflects the potential importance of the local duct requirements on the system. Consequently a second duct design was experimentally evaluated which incorporated these changes and resulted in a measured loss reduction of $25 \%$ (see Table 3). Note that this was achieved without any detrimental effects on the upstream pressure field or balance of the system. Whilst varying the area distribution is clearly beneficial, the result also highlights the importance of the local system requirements and the benefits of a more integrated design approach (for example, where consideration can be given to the size and position of the radial drive shaft as part of the duct aerodynamic design process).

\begin{tabular}{|cc|c|c|c|}
\hline \multicolumn{2}{|l}{ Loss $\lambda=\frac{\tilde{P}_{A}-\tilde{P}_{B}}{\tilde{P}_{A}-\tilde{p}_{A}}$} & $\begin{array}{c}\lambda_{\text {A-B }} \\
\text { (Duct 1) }\end{array}$ & $\begin{array}{c}\lambda_{\text {A-B }} \\
\text { (Duct 3) }\end{array}$ & $\begin{array}{c}\lambda_{\text {A-B }} \\
\text { (Duct 4) }\end{array}$ \\
\hline Datum & CFD & 0.132 & 0.127 & 0.132 \\
& Exp. & 0.212 & 0.195 & 0.176 \\
\hline Design 2 & CFD & 0.093 & $*$ & $*$ \\
& Exp. & 0.144 & 0.146 & 0.152 \\
\hline
\end{tabular}

Table 3 S-Duct Losses (*Not Computed) 


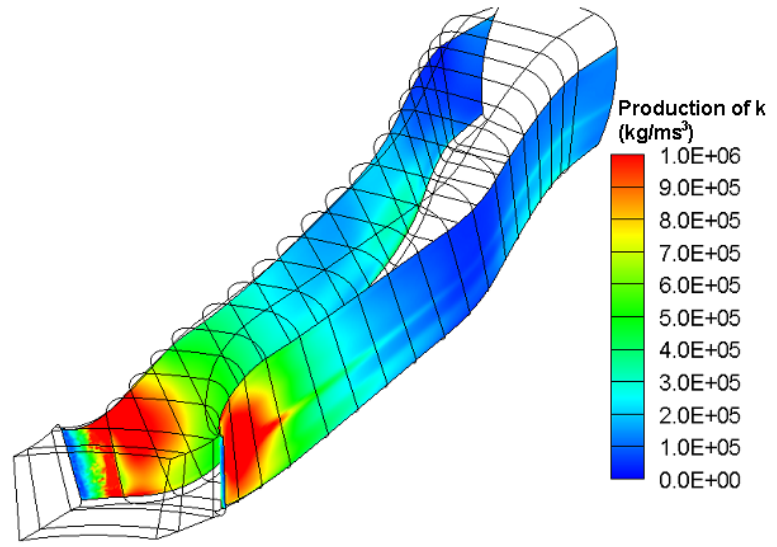

(a) Side Walls

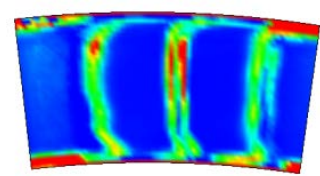

$\mathrm{x} / \mathrm{L}=10 \%$

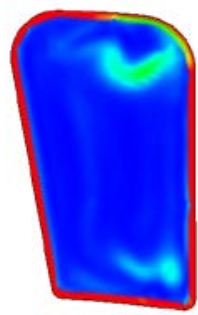

$\mathrm{x} / \mathrm{L}=\mathbf{4 0} \%$

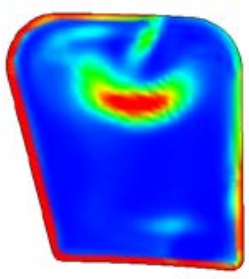

$\mathrm{x} / \mathrm{L}=\mathbf{7 0} \%$

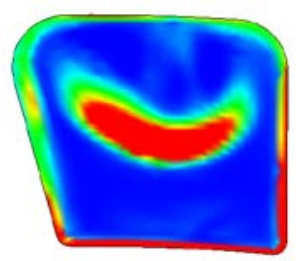

$\mathrm{x} / \mathrm{L}=\mathbf{1 0 0} \%$

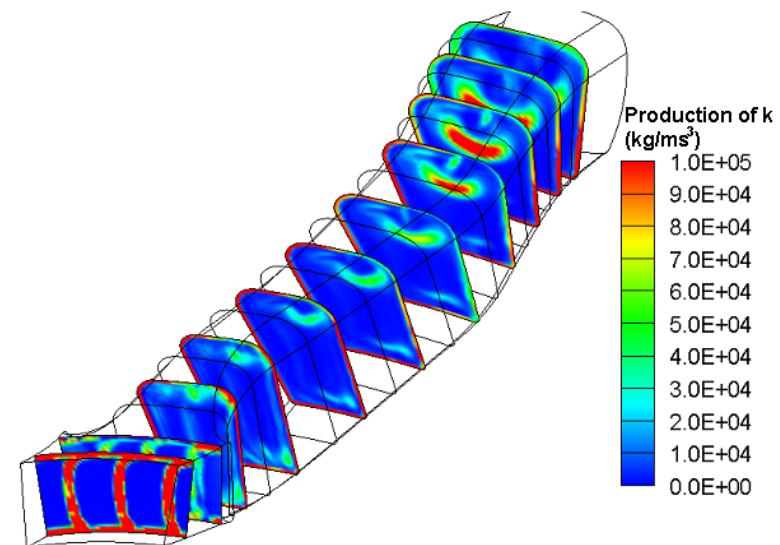

(b) Internal Flow

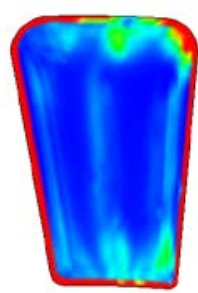

$\mathrm{x} / \mathrm{L}=\mathbf{2 0} \%$
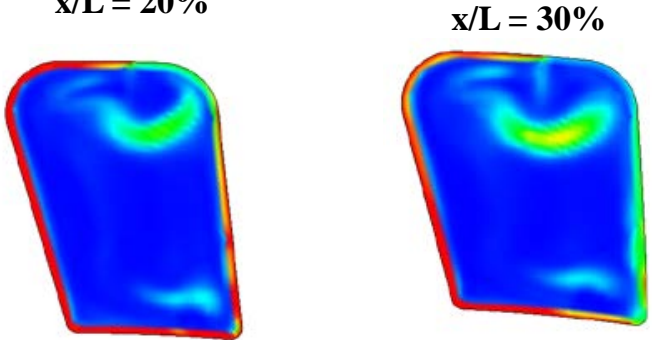

$\mathbf{x} / \mathbf{L}=\mathbf{5 0} \%$

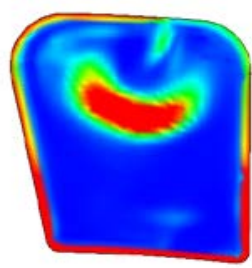

$\mathrm{x} / \mathrm{L}=\mathbf{8 0} \%$

$$
\begin{gathered}
\text { production-of-k } \\
1.0 \mathrm{E}+05 \\
9.0 \mathrm{E}+04 \\
8.0 \mathrm{E}+04 \\
7.0 \mathrm{E}+04 \\
6.0 \mathrm{E}+04 \\
5.0 \mathrm{E}+04 \\
4.0 \mathrm{E}+04 \\
3.0 \mathrm{E}+04 \\
2.0 \mathrm{E}+04 \\
1.0 \mathrm{E}+04
\end{gathered}
$$$$
0.0 \mathrm{E}+00
$$

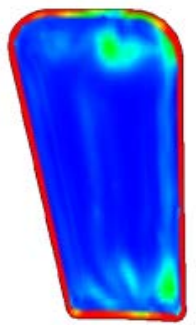

$\mathrm{x} / \mathrm{L}=\mathbf{6 0} \%$

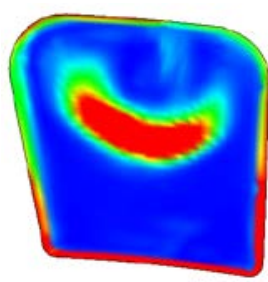

$\mathrm{x} / \mathrm{L}=\mathbf{9 0} \%$

(c) Internal Flow Planes

Figure 18 Production of Turbulent Kinetic Energy (Loss) 


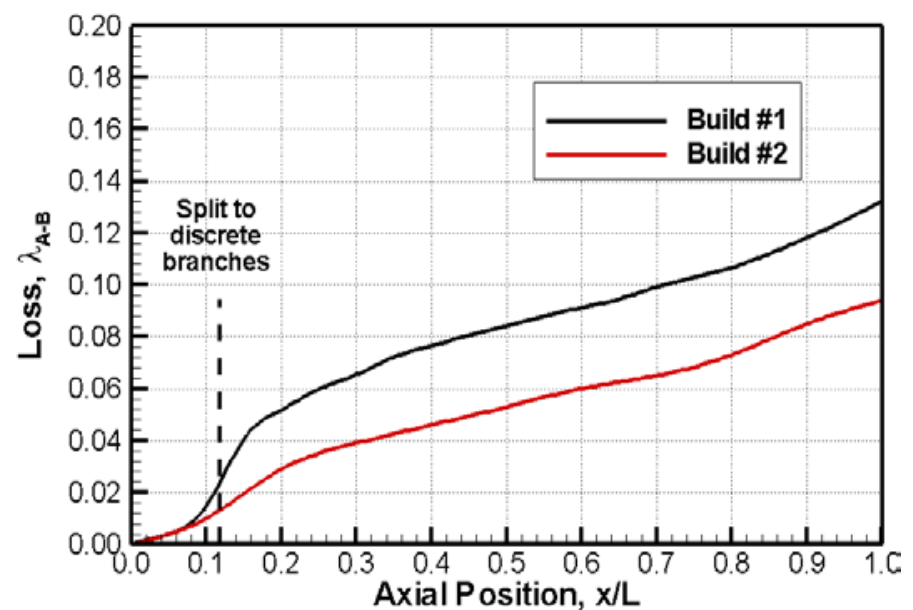

Figure 19 CFD Prediction of Loss Development

\section{Conclusion}

An investigation has been undertaken into the ducting system required to deliver core air flow from the compression system to the heat exchanger modules of an intercooled aero gas turbine engine. The system requirements have been identified which included the basic system geometrical requirements, consideration of local mechanical constraints and consideration of the relevant performance criteria. From these requirements a ducting system concept was developed in which swirl from the upstream compressor spool was allowed to pass into the ducting system. This enabled enlarged circumferential gaps to be created whilst avoiding forcing of the upstream compressor spool. In this way the local geometrical requirements associated with an actual engine environment can be accommodated (e.g. core access for ancillary services, radial drive shafts etc.). Moreover, the compressor OGV were successfully integrated into the first bend of the S-Duct providing potential length and weight savings.

Numerical investigations were initially used to explore the design space and investigate the relative trade-off between system loss, upstream pressure field effects (i.e. rotor forcing) and uniformity of the flow distribution to the heat exchanger modules. A ducting system was then designed and experimentally evaluated on a fully annular isothermal test facility. In terms of overall performance, the duct system was well balanced with virtually the same mass flow in each duct branch (to within $\pm 1 \%$ of the total mass flow). The average total pressure loss was $20 \%$ of the OGV exit dynamic head and this varied by less than $\pm 1 \%$ between duct branches. Additionally the exit flow field from each branch was broadly similar. Based on the datum system performance a more refined geometry was 
developed in which the duct losses were reduced to $15 \%$ of the OGV exit dynamic head. This performance information enables the potential benefits of the intercooled aero-engine concept to be evaluated.

\section{Acknowledgments}

This work was undertaken as part of the European Union (EU) Framework 6 Project NEWAC: NEW Aero engine Core concepts (FP6-030876). As part of this the authors would like to acknowledge the support of RollsRoyce plc., particularly Andrew Rolt, Sam Mason and Rory Steiger (Strategic Research Centre) and Neil Harvey and Chris Hall (Compression Systems).

\section{References}

[1] Advisory Council for Aeronautical Research in Europe, ACARE, 2001, "European Aeronautics - A Vision for 2020”.

[2] Wilfert, G., Sieber, J., Rolt, A., Baker, N., Touyeras, A., Colantuoni, S., 2007, “New Environmental Friendly Aero Engine Core Concepts,” ISABE-2007-1120.

[3] Cumpsty, N. C., 2009, "Preparing for the Future: Reducing Gas Turbine Environmental Impact”, ASME Paper No. GT2009-60367.

[4] A’Barrow, C., Carrotte, J.F., Walker, A.D. and Rolts, A.M., 2011, “Aerodynamic Performance of a Coolant Flow Off-Take Downstream of an OGV”, ASME Paper GT2011-45888.

[5] Walker, A. D., A’Barrow, C., Carrotte, J. F. and Rolt, A. M., 2011, “Aerodynamic Design of the Cooling Flow Duct System for an Intercooled Aero Engine”, ISABE-2011-1257.

[6] Britchford, K. M., Carrotte, J. F., Kim, J. H. and Hield, P. M., 2001, "The Effect of Operating Conditions on the Aerodynamic Performance of an Integrated OGV S-Shaped Duct", ASME 2001-GT-0347.

[7] Walker, A. D., Carrotte, J. F. and Rolt, A. M., 2009, "Duct Aerodynamics for Intercooled Aero Gas Turbines: Constraints, Concepts and Design Methodology,” ASME Paper No.GT2009-59612.

[8] Britchford, K.M., Carrotte, J.F., Stevens, S.J. and McGuirk, J.J., 1994, “The Development of the Mean Flow and Turbulence Structure in an Annular S-Shaped Duct”, ASME Paper No. 94-GT-457.

[9] Sieverding, C. H., 1985, "Recent Progress in the Understanding of Basic Aspects of Secondary Flows in Turbine Blade Passages”, ASME Journal of Engineering for Gas Turbines and Power, 107, pp. 248-157. 
[10] Stevens, S. J., Harasgama, S. P. and Wray, A. P., 1984, “The Influence of Blade Wakes on Combustor Shortened Pre-diffusers,” Journal of Aircraft, 21, pp. 641-648.

[11]Klein, A., 1988, "The Relation between Losses and Entry Flow Conditions in Short Dump Diffusers for Combustors,” Z. Flugwiss, Weltraumforsch, (12), pp. 286-292.

[12]Zierer, T., 1993, "Experimental Investigation of the Flow in Diffusers Behind an Axial Flow Compressor," ASME Paper No. 93-GT-347.

[13] Carrotte, J. F., Young, K. F. and Stevens, S. J., 1995, "Measurements of the Flowfield within a Compressor Outlet Guide Vane Passage,” ASME Journal of Turbomachinery, 117, pp. 29-37.

[14] Barker, A. G., and Carrotte, J. F., 2001, “The Influence of Compressor Exit Conditions on Combustor Annular Diffusers - Part I: Diffuser Performance,” AIAA Journal of Propulsion and Power, 17, pp. 678-686.

[15] Barker, A. G., and Carrotte, J. F., 2001, “The Influence of Compressor Exit Conditions on Combustor Annular Diffusers - Part II: Flow Redistribution within the Diffuser,” AIAA Journal of Propulsion and Power, 17, pp. $687-694$.

[16] Wray, A. P. and Carrotte, J. F., 1993, “The Development of a Large Annular Facility for Testing Gas Turbine Combustor Diffuser Systems”, AIAA-93-2546.

[17]Lapworth L., Shahpar S., 2004, “Design of Gas Turbine Engines using CFD,” ECCOMAS 2004, Eds., Neittannmaki, et al., Finland.

[18] Shahpar S. and Lapworth L., 2003, "PADRAM: Parametric Design and Rapid Meshing System for Turbomachinery Optimization”, ASME Paper No. GT2003-38698

[19] Cumpsty, N. A, 2004, “Compressor Aerodynamics”, Krieger Publishing Company; 2nd Ed.

[20] Klein, A., 1995, “Characteristics of Combustor Diffusers”, Progress in Aerospace Science, 31(9), pp. 171-271. 